\title{
DILLERDE CINSIYET ALMANCA VE TÜRKÇEDE CINSIYET KAVRAMLARI
}

\author{
Gender in Languages \\ Gender Concepts of German and Turkish
}

\section{Dr. Fatma ÖZTÜRK DAĞABAKAN ${ }^{*}$}

\section{ÖZ}

Bu makalede, dünya dillerinin hemen hemen hepsini ilgilendiren cinsiyet konusuna değinildi. Çıkış noktası olarak cinsiyet kavramının dildeki iki türünden bahsedilerek, dilbilgisel cinsiyet ve biyolojik cinsiyet oluşumları ortaya kondu. Bu kavramlar arasındaki farklılıklar, benzeyen durumlar, uygun olan karşılıklar belli başlı örnekler ile okuyucuya sunulmaya çalışıldı. Aynı zamanda dilbilgisel cinsiyetin dildeki önemi, hangi dillerde hangi cinsiyetin ne şekilde yer aldığı konusu da çalışmada belirtilerek, Türkiye'de fazla araştırmanın bulunmadığı bir alan hakkında açıklamalar oluşturuldu. Dilbilgisel cinsiyet bulunmayan bir dil olarak Türkçenin durumu cinsiyet konusu açısından ele alınarak dilbilgisel cinsiyet dili olan Almanca ile bir mukayese yapıldı ve her iki dil arasındaki benzerlikler, farklılıklar, karşılıklar tanımlanarak her iki dil arasında bir inceleme yapılmaya çalışıldı.

Anahtar sözcükler: Genus, Sexus, dilbilgisel cinsiyet, biyolojik cinsiyet, artikel, Türkçe, Almanca

\section{ABSTRACT}

This article touched on the issue of gender concerns almost all world languages. Two types of language being referred to the concept of gender as a starting point, in formations were grammatical gender and biological gender. The differences between these concepts, similar to the circumstances, the appropriate provisions made to be presented to the reader with the major examples. But also the importance of grammatical gender in the language, in which the languages which of gender in what way the subject of this study also is specified. Explanations about the absence of further research in Turkey, an area was created. Turkish as a language without grammatical gender status was discussed in terms of the issue of gender. A comparison was made with the German as a grammatical gender language, and similarities between the two languages, differences in responses between the two languages, each defining an investigation was attempted.

Key words: Genus, Sexus, grammatical gender, biological gender, article, Turkish, German

\footnotetext{
*Atatürk Üniversitesi Edebiyat Fakültesi Alman Dili ve Edebiyatı Bölümü Öğretim Üyesi
} 


\section{Giriş}

Dil, insanların en önemli iletişim aracıdır ve her yaşam alanında merkezi bir rol oynamaktadır. Dil, ilk etapta akla gelen iletişim işlevi dışında, insanların, dünyayı algılaması, kavraması ve tecrübelerini düzenleyip harmanlaması için bir araç görevi de üstlenmektedir. Bununla beraber dil, toplumun değer ve norm kavramlarını yansıtarak her zaman toplumsal oluşumlara bağlılı̆ını açı̆ga vurmaktadır. Bu şekilde, toplumsal oluşumlar, dilde kültürel izler bırakarak, dili, söz konusu kültürde geçerli olan niteliklerin göstergesi yapmaktadır.

Dil, toplumsal olayları yansıttığı gibi, hüküm süren değerleri ve normları onaylayıp destekleyerek veya istenmeyen pozisyonları bastırarak onları içinde de barındırmaktadır. Hüküm süren değerler ve istenmeyen pozisyonlar kültürel bir yapıya sahip olduğu gibi, dilin yapısal şekline de dayanabilmektedir. Dilin bu süreci, belli içeriklere şekilsel bir hacim kazandırmak için kullanılan bilinçli bir ișlemdir. (lrmen, Sanders 2000: 1 http://www.psychologie.uniheidelberg.de/html, 16.08.2006) Bu bilinçli işlemi ve kültürel özelliklerin dilde ne ölçüde yansıma bulduğunu dil ve cinsiyet perspektifinde de görmek mümkündür.

Bu çalışma ile cinsiyet kavramının dildeki konumu incelenmeye çalışılacaktır. Dünya dillerindeki cinsiyet olgusu hangi temellerde yapılanmaktadır? Cinsiyet hangi yapılarda dile yerleşmektedir? Dilde cinsiyet ayrımını görmek mümkün müdür? Dilin cinsiyet içeriği hangi dönemlerde oluşmuştur ve bunun sebeplerini, oluşum sürecini açıklayan kuramlar ne şekilde kendilerini ifade etmektedirler? Birbirini tamamlayan bu soruların cevaplandırılmasının yanı sıra Almanca ve Türkçedeki cinsiyet içeriğinin bir mukayesesi de bu çalışma ile hedeflenmektedir.

\section{Dillerdeki Biyolojik Cinsiyet ve Dilbilgisel Cinsiyet}

Dillerin cinsiyet içeriği, günümüzde, farklı açılardan ele alınıp birçok yöntem oluşturularak, değişik yaklaşımlar bulmuştur. Bu yaklaşımlarda feminizm akım, sosyoloji, dilbilim, edebiyat gibi birçok alan yönteminin etkisi görülmektedir.

Dilde cinsiyet kavramı genel olarak biyolojik ve dilbilgisel cinsiyet olmak üzere iki bakış açısından değerlendirilmektedir. Dilde yapısal bir özellik gösteren "dilbilgisel cinsiyet (Genus), çekimli dillerdeki cinsiyetin dilsel tanımıdır" (Müller 1860: 1) ve dilbilimin başlı başına bir çalışma konusunu oluşturmaktadır.

Dilbilgisel cinsiyet, biçimsel dilbilgisi kategorisidir. İsim cümlesinin şekilsel tanımında belirleyicidir ve önemli işlevlere sahiptir. İsmin dilbilgisel cinsiyeti, 
isim kökünü artikel ve sıfat tamlaması ile hal ve sayıya göre yapılandırmaktadır. Böylece dilbilgisel cinsiyet hal ve sayı belirtisinin yanı sıra, isimde şekilsel düzen ve denge sağlamakta, ayrıca isim öbeğinin tanımlanmasına katkıda bulunmaktadır. Zamirlerde yine ilgili hal durumunu yapılandırarak metinsel bütünlüğü sağlamaktadır. (Klann - Delius 2005: 20).

Biyolojik cinsiyet (Sexus), dilbilgisel cinsiyet (Genus) boyutunda dilbilimsel bir özellik bulundurmamakla beraber, biyolojik-sosyal cinsiyeti gösteren dilsel ifadeler bu alanda ele alınmaktadır. "Saussure terminolojisinde, 'Genus' gösterenin, 'Sexus' ise gösterilenin sınıflandırılmasına işaret etmektedir." (Pittner 1998: 153) Yani biyolojik cinsiyet, canlıların doğal cinsiyetleridir ve erkek, dişi olarak iki kategoride sınıflandırılmaktadır.

Biyolojik cinsiyet genelde bütün dillerde ifade bulmaktadır. Dilbilgisel cinsiyet bulunmayan bir dil olarak, Türkçede de, diğer bütün diller gibi biyolojik cinsiyet görülmektedir. Biyolojik cinsiyet, kişinin sahip olduğu cinsiyetinin sözcüğe yansıması ile özellikle kişi terimlerinde öne çıkmaktadır. Örneğin Türkçedeki kadın-erkek, anne-baba, oğul- kız, bay-bayan; Almancadaki Mann-Frau, MutterVater, Sohn-Tochter, Herr-Frau gibi sosyal ve biyolojik cinsiyet içeriği ile örtüşen ifadeler, sözü anlamsal boyutta vurgulayan sözcüklerdir. Aynı zamanda, dillerde, tavuk-horoz, öküz-inek, koyun-koç, keçi-teke gibi hayvan cinsiyetlerine işaret eden sözcük çiftleri de bulunur.

Feminist dilbilimde, kadın-erkek - Mann-Frau, anne-baba - Mutter-Vater, oğul- kız - Sohn-Tochter, bay-bayan - Herr-Frau gibi kişisel tanım adlandırmalarında biyolojik cinsiyet ile dilbilgisel cinsiyet arasında sıkı bir ilişkinin varlığı savunulmaktadır. (Reis 20011: 751) Almancada, kişi hitaplarında bayan - erkek ayrımı yapmadan, hitap edilen her kişiye eril bir adlandırılmanın yakıştırılması, feministleri, kadınların aşağılandığı yönünde düşünmeye götürmektedir ve böylece dilde eşitlik arayışına sokmaktadır. Almancada, Türkçeden farklı olarak çoğunlukla meslek isimlerinde eril ve dişil ayrımı söz konusudur. Türkçedeki müdür müdire tanımları Almancada birçok mesleki adlandırmada yer bulmaktadır. Örneğin Türkçede, öğretmen, doktor veya mühendis gibi meslek isimleri ifade edildiğinde bir ayrım yapmak mümkün değildir. Hitap edilen kişiye göre, öğretmen, doktor veya mühendis, bayan da olabilir erkek de. Burada, bu adlandırmanın içeriği, hitap edilen kişiye ve metnin bağlamına göre anlam bulmaktadır. Almancada ise, bu kişisel adlandırmalar, kişi cinsiyetlerine göre birer tanım almaktadır. Erkeklerin meslekleri veya kişisel tanımları 'der' artikelini alırken, bayanlarınki dişil olan 'die' artikeli ile tanımlanmaktadır ve bayanların meslek isimlerinde çoğunlukla ismin sonuna '-in' eki ilave edilmektedir: 
- der Lehrer - die Lehrerin; erkek öğretmen - bayan öğretmen

- $\quad$ der Arzt - die Ärztin; erkek doktor - bayan doktor

- der lngenieur - die Ingenieurin; erkek mühendis - bayan mühendis

Genel bir hitap söz konusu olduğunda, hitap genellikle 'der' artikelinin tanımladığı eril isim şekli ile yapılmaktadır. Bu artikel "generisches Maskulinum" (Pober 2007: 56) (bir sözcügün genelleyen eril şekli) olarak adlandırılmakta ve bir genelleme yapıldığında veya biyolojik cinsiyet önemsiz olarak görüldüğünde kullanılmaktadır:

- die Lehrer von dieser Schule; bu okulun öğretmenleri (bu okulun erkek öğretmenleri)

'Bu okulun öğretmenleri' ifadesi, Türkçede, okulun bütün öğretmenlerine işaret etmektedir. Almancada da bu söylem, anlam olarak okulun bütün öğretmenlerini hedeflemektedir. Fakat yapı olarak 'Lehrerin' (bayan öğretmen) yerine 'Lehrer' (erkek öğretmen) sözcügünün çoğul kipi kullanıldığı için Alman feministler bu durumu bir aşağılanma ve kadının ikinci plana atılması olarak algılamaktadırlar. Bu yüzden, hitaplarda, dişil artikelin ve isim tanımının kullanılması$\mathrm{n}$ talep etmektedirler. Nitekim birkaç seneden beri onların bu amaçlarını gerçekleştirecek adımlar atılıp isteklerini yürütecek kanuni düzenlemeler yapılarak hitaplarda '/in' uygulamasına başlanmıştır. (Lehrer/in; Student/in)

'Generisches Maskulinuma' benzer bir kullanımın Türkçede de var olduğunu ileri süren Frederike Braun, Geschlecht im Türkischen adlı eserinde genç, insanoğlu, çocuk gibi ifadelerde bu tür bir anlam değerlendirmesinin olduğunu açıklamaya çalışmaktadır. (Braun 2000: 78)

Feminist dilbilimcilerin düşüncelerine karşıt görüşlerle cevap veren dilbilimciler de bulunmaktadır. Profesör Dr. Elisabeth Leiss, kişisel tanım adlandırmalarında biyolojik cinsiyet ile dilbilgisel cinsiyet arasında sıkı bir ilişkinin varlığını savunan Feminist dilbilimcilerin aksine, bu iki cinsiyet arasında sıkı bir bağın bulunmadığını ileri sürmektedir. (Tafel 1997: 66) Leiss, aynı şekilde, Jacob Grimm'in desteklediği, dilbilgisel cinsiyetin, biyolojik cinsiyetin bir türevi olduğu düşüncesini savunan kurama da itiraz etmektedir. (Pittner 1998: 153) Jacob Grimm, dilbilgisel cinsiyetin eril, dişil ve yansız oluşumlarını şu özelliklere dayandırarak tanımlamaktadır: 
Eril daha önceki, daha büyük, daha sağlam, daha sert, daha hızl, aktif, hareketli, üretken gibi; dişil daha sonraki, daha küçük, daha yumuşak, sessiz, güçsüz, alıcı gibi; yansız ise üretilmiş, işlenmiş, maddesel, genel, gelişmemiş, kolektif, duygusuz, cansız gibi görünüyor. (Grimm 1870:357) (Pittner 1998: 153)

Jacob Grimm'in bu açıklamasına göre, bir isme tanımlanabilecek dilbilgisel cinsiyet, söz konusu sözcüğün kavramsal özelliklerinden destek almaktadır. "Böyle bir dilbilgisel cinsiyet anlambilimi, isimlerin dilbilgisel cinsiyetlerini açılamak için kullanılmaktadır. Buna göre, el ayağa oranla daha dişildir. Çünkü el ayaktan daha küçüktür." (Pittner 1998: 153) Dilbilgisel cinsiyetin biyolojik cinsiyet ile bu gibi bir oran ilişkisi içerisinde olması bu kurama göre her zaman mümkün olmak zorundadır. Oysa die Hand (el) - der Fuß (ayak) eşlemesinde uyum gösteren kuram, das Bein (bacak) - der Arm (kol) eşlemesinde aynı uyumu sağlamamaktadır. Kol, bacağa oranla daha küçük, daha güçsüz, daha zayıf, daha yumuşak olmasına rağmen, daha önceki, daha büyük, daha sağlam, daha sert, daha hızlı, aktif, hareketli, üretken özellikleri belirten eril artikel der ile tanımlanmıştır. Bacak ise koldan daha büyük, daha güçlü, daha sağlam olmasına rağmen ve kurala göre der artikeli ile tanımlanması gerekirken, üretilmiş, işlenmiş, maddesel, genel, gelişmemiş, kolektif, duygusuz, cansız özellikleri barındıran yansız das artikeli ile tanımlanmıştır. Öyleyse, dilbilgisel cinsiyetin, biyolojik cinsiyetin bir türevi olduğunu her durum için söylemek mümkün değildir.

Dilbilgisel Cinsiyetin Oluşum Süreci ve Dünya Dillerinde Dilbilgisel Cinsiyet

Dilbilgisel cinsiyetin kökeni, motivasyonu ve işlevi hakkındaki tartışmalar oldukça eskilere dayanmaktadır ve bugün bile bir çözüme ulaşmış bulunmamaktadır. (Tafel 1997: 66) Bunlardan en önemlilerinden birini ise dilbilgisel cinsiyetin oluşum süreci ile ilgili araştırmalar yapılandırmaktadır. Bu oluşum süreci, dilbilgisel cinsiyetin nasıl ve ne zaman oluştuğu, aynı zamanda da niye böyle bir dilbilgisel yapıya ihtiyaç duyulduğu şeklindeki yaklaşımlarla sorgulanmaktadır.

Dilbilgisel cinsiyetin çıkış noktası ve oluşum süreci ile ilgili, Jacob Grimm'in, yukarda değinilen kuramı gibi birçok kuram bulunmaktadır. Bu kuramlar, yapısal ve semantik olmak üzere iki ana gruba ayrılmaktadır. Semantik kuramda, dilbilgisel cinsiyet "ismin anlamı ile" (Bewer 2004: 90) ilişkilendirilmektedir ve biyolojik cinsiyet ile dilbilgisel cinsiyet arasında bir bağlantı olduğu savunulmaktadır. Semantik kuramlardan "Animizm kuramı ve cinsiyet kuramı" (Fischer 2005: 55) geniş bir destek bulmuştur. 
Tarihte ilk dilsel cinsiyet ayrımı 5. yüzyıl sofistlerinden Protagoras'a mal edilmektedir. Protagoras, Grekçede eril, dişil ve üçüncü cinsiyet olmak üzere üç farklı cinsiyetten bahsetmektedir. Protagoras sonrasında Aristo'da da bu üçlü cinsiyet ayrımı görülmektedir. Aristo da Protagoras gibi cinsiyetin eril, dişil türlerini kabul etmiş, fakat Protagoras'ın üçüncü cinsiyet dediği türün ya eril ya da dişil olduğunu görünce bu üçüncü cinsiyete 'aradaki cinsiyet' adının verilmesini uygun bulmuştur. Daha sonra ise bu cinsiyet 'ya - ya da' olarak adlandırılmıştır. (Lyons 1980: 11) Protagoras, semantik - cinsiyet kuramlarının (semantischsexualistische Genustheorien) öncüsü olarak kabul etmektedir. Bu kuramların temsilcileri, biyolojik cinsiyetin, dilbilgisel cinsiyeti belirlediği düşüncesini ileri sürmektedirler. (Weber 2001: 15)

Jacob Grimm'in kuramı, semantik - cinsiyet kuramlar arasında yer almaktadır. Jacob Grimm bu kuramın en tanınmış temsilcilerindendir. Jacob Grimm'den (1785-1863) başka, Humboldt (1769-1859), Adelung (1732-1806) ve Herder (1744-1803) de bu kuramın temsilcilerindendirler. (Scholz 2007: 12)

Semantik kuramlarda dil dışı etkenler söz konusudur ve ilk kavimlerin "animizm" (Fischer 2005: 55) düşüncesi bu kuramları yapılandırmaktadır. Johann Gottfried Herder'e ait olan bu semantik - animizm kuramında, ilk kavim insanlarının, animist yaklaşımla bütün sözcüklere soyut ya da somut ifadeler ile birer biyolojik cinsiyet taktıkları kabul edilmektedir. Dilbilgisel cinsiyetin önceleri sahip olduğu işlev yani biyolojik cinsiyetin belirtilmesi bu kuram yoluyla açılanmaya çalışılmıştır. Animizm kuramı uzun yıllar varlığını korumuştur. (Fischer 2005: 55)

Yapısal kuramlar ise dilbilgisel cinsiyeti yapı açısından ele alan kuramlardan oluşmaktadır. Semantik kuramlara tamamen zıt bir anlayış ile oluşmuş olan bu kuramlar "biçimsel - dilbilgisi kuramları" (Weber 2001: 27) başlı̆̆ altında toplanmaktadır. Bu kuramlar ise iki ayrı bakış açısında yön bulmaktadır. Bunlar, "işlevsel olmayan biçimsel - dilbilgisi kuramları ve işlevsel biçimsel - dilbilgisi kuramları" (Heina 2006: 3) (nicht-funktional formal-grammatische und funktional formal-grammatische Genustheorie) şeklinde tanımlanmaktadır. Bu biçimsel bakış açısı "morfolojik - semantik" (Weber 2001: 27) düşüncelerle tamamlanmaktadır. Bu kuramdan ilk olarak, dilbilgisel cinsiyet ile biyolojik cinsiyetin birbirinden farklı olduğunu ifade eden Aristo bahsetmiştir.

Bu kuramın temsilcileri dilbilgisel cinsiyetin yapısal bir boyutta, yani dilbilgisel yapı düzleminde değerlendirilmesi gerektiğini savunmaktadırlar. Onlara göre, dilbilgisel cinsiyet biyolojik cinsiyetten tamamen farklı bir şekilde yer bulmaktadır ve nitelendirdiği isimlerin biyolojik cinsiyeti ile arasında hiçbir anlamsal 
bağ bulunmamaktadır. îşlevsel biçimsel - dilbilgisi kuramlarının önde gelen temsilcilerini 18. yüzyılın ikinci yarısının "rasyonalistleri" (Fischer 2005: 52) oluşturmaktadır. Bunlardan Werner Meiner, dilbilgisel cinsiyetin her türlü semantik özelliğini reddetmektedir ve bunun oluşumunda tamamen işlevsel bir etken bulmaktadır. Aynı şekilde Weisgerber de dilbilgisel cinsiyet türlerinin işlevlerini Werner Meiner gibi, onların sözdizimsel oluşumlarında bulmaktadır. (Fischer 2005: 52) August Schleicher de, Werner Meiner ve Aristo'nun yanı sıra, işlevsel olmayan biçimsel - dilbilgisi kuramlarının öncüleri arasında sayılmaktadır. Indogermanist Kral Brugmann ise işlevsel olmayan biçimsel - dilbilgisi kuramları hakkında yaptığı ayrıntılı çalışmasıyla kendinden söz ettirmektedir. (Weber 200ı: $28-29)$

Oluşum kuramlarından en yenisini Antoine Meillet'in temsil ettiği adıl kuramı (pronominale Entstehungstheorie) oluşturmaktadır. Bu kuram, semantik cinsiyet kuramlarından da, biçimsel - dilbilgisi kuramlarından da izler taşımaktadır. Bu kuram, dilbilgisel cinsiyetin yapısal temelini adıllarda aramak gerektiğini savunmaktadır. (Weber 2001: 13)

Dilbilgisel cinsiyet (Genus), biyolojik cinsiyetten (Sexus) tamamen farklı bir tanımlama içerisinde yer almaktadır. Dilbilgisel cinsiyetin bu farkı, sözcüklerin dilbilgisel özelliklerinde yatmaktadır, yani bu terim, sözcüklerin sınıflandırılmasına yönelik bir kullanıma sahiptir.

Dilbilgisel cinsiyet, dilbilimde, özellikle ad alanında morfolojik bir altsınıftır. (Gerber 2008: 30) Bu sözcük kategorisi, bazı dillerde isme dilbilgisel boyutta genelde eril, dişil ya da yansız olma özelliği sağlamaktadır. Dilbilgisel cinsi anlamsal ölçütlerle tanımlamak mümkün değildir. (Vardar 1998: 60) Dilbilgisel cinsiyette bir ismin cinsiyeti onun artikeli ile belirlenmektedir. Buna göre, isimlerin, dilbilgisel yapılarına göre üç grupta sınılandırılması uygundur, fakat bu grupların eril, dişil ve yansız olarak adlandırılmaları tamamen tesadüfídir, yani sadece eril ve dişil cinsiyetten oluşan ve dünyevi cinsiyeti belirten biyolojik cinsiyet ile örtüşmez. Dilbilgisel cinsiyet ismin dilbilgisel sınıflandırmasından başka bir şey değildir. (Drosdowksi 1972: 290) Bazı dillerde bulunmayan, bazılarında ise büyük bir rol oynayan dilbilgisel cinsiyet kavramının, bulunduğu dildeki işlevi ve önemi birçok açıdan ele alınmaktadır. Dilbilgisel cinsiyet, daha önce de belirtildiği gibi, hiçbir şekilde biyolojik cinsiyet ile örtüşmemektedir. Örneğin, dilbilgisel cinsiyeti, bugün de eskide olduğu gibi, hiçbir şey kaybetmeden kullanan Almancadaki, evlenmemiş bayan anlamındaki das Fräulein ya da kız anlamındaki das Mädchen, biyolojik cinsiyetlerinin dişil olmasına rağmen, biçim olarak yansız dilbilgisel cinsiyeti gösteren das artikeli ile belirtilmektedir. Dilbilgisel cinsiyet kavramları, sözcüklerin biçimsel özelliklerine işaret ettikleri için Almanca gibi 
bazı dillerde bu nedenle biyolojik cinsiyet ile dilbilgisel cinsiyet göstergesi benzeşmemekte ve kimi sözcükler, belirttikleri nesnenin dişi ya da erkek olmalarına karşın yansız sayılmaktadır. (Aksan 1998: 87)

İsimlerin cinsiyet konusu, dillerde oldukça önemli bir yere sahiptir. HintAvrupa dillerinde genelde eril, dişil gibi iki veya eril, dişil, yansız gibi üç türden oluşan dilbilgisel cinsiyet, özellikle Bantu dilleri gibi sınıflandırmalı dillerde (klassifizierende Sprachen) daha fazla ayrıma sahiptir. Bu dillerdeki cinsiyet sınılandırması kişiler, canlılar, cansızlar, eşyalar, organizmalar, vasıflar, yönler olarak ortaya çımmaktadır. (Sowinski 1974: 66) Rusça ve Arapça gibi birkaç dilde ise eylemler bile cinsiyet oluşumu göstermektedir.

Dünya dillerinin bazısında dilbilgisel cinsiyet bulunmamaktadır. Bazı dil ailelerine bağlı dillerde ise ya yoğun bir şekilde kullanılmakta, ya da zamanla kaybolmaktadır. Örneğin Hint-Avrupa dil ailesindeki İran dilinde önceleri bulunan üç dilbilgisel cinsiyetin daha sonra yok oluşu, yani dilbilgisel cinsiyetin bu dillerdeki kullanımı geçmişe dayalı bir kalıtım ile sağlanmaktadır, tamamen yeniden edinilmemektedir.

Dünya dilleri dilbilgisel cinsiyet bulunanlar ve bulunmayanlar olarak ikiye ayrılmaktadır. Bunlardan, genel olarak Hint - Avrupa dilleri Ailesi (İranca ve Ermenicede Kayı), Kuzey - Kafkas dilleri, Avustralya dilleri, Nil-Kongo dilleri, Papua dilleri, Dravid dilleri, Kelt (Sibiryaca), Afro-Asya dilleri, Boşiman dilleri, Kuzey Amerika Kızılderili dilleri grubu cinsiyet ayrımı yapmakta, Ural dilleri, Altay dilleri, Tay dilleri, çoğu Amerika dilleri, Bask dilleri, Tibet-Birman dilleri, Eski Sibirya dilleri, Eskimo- Eski Sibirya dilleri, Malayca-Endonezya dili grubunda ise dilbilgisel cinsiyete rastlanmamaktadır. Türkçe de Altay dillerinin Türk Dil Grubu kategorisinde yer alan bir dil olarak dilbilgisel cinsiyet bulundurmamaktadır.

Dilbilgisel cinsiyet bulunduran dillerde şekilsel olarak birçok farklılık görülmektedir. Genelde cinsiyet ayrımına rastlanan Hint-Avrupa dillerinden Ermenice, İngilizce (kişi zamirleri haricinde) ve İran dilinde cinsiyet söz konusu değildir. İtalyanca, Fransızca, Katalanca, İspanyolca, Portekizce gibi çoğu Roman dillerinde; bugün yaşayan Litvanya ve Let dilleri gibi Baltık dillerinde; Hami-Sami grubundan Arapça, ibranice, Aramca, Amharca dillerinde eril-dişil ayrımı bulunmaktadır.

Doğu i̇skandinav dilleri adı altındaki Danca, İsveççe ve Norveççe (muhafazakâr Bokmal yazı dili) Utrum (eril ile dişilin birleştirilmiş hali) ve Neutrum (yansız, cinsiyetsiz) olmak üzere iki dilbilgisel cinsiyet tanımaktadır. 
Dilbilgisel cinsiyetin eril-dişil-yansız ayrımın birçok dilde görmek mümkündür. Önceleri tümünde eril-dişil-yansız sınıflandırması bulunan Hint-Avrupa dil ailesinden Germen dillerinde günümüzde yalnızca Almanca, Hollandaca, Norveççe (muhafazakâr Bokmal haricinde), İzlandaca, Faroe Dili ve Frizce bu üç cinsiyeti muhafaza etmişlerdir. Yine Roman dillerinden Latince ve Rumence, Slav dillerinden Bulgarca, Polonyaca, Rusça, Slovakça, Çekçe, Ukraynaca, Sorb dili ve Slovencede, ayrıca Arnavutça, Sanskritçe ve Yeni Yunancada da üç dilbilgisel cinsiyet bulunmaktadır.

\section{Dünya Dillerinde Dilbilgisel Cinsiyet}

\begin{tabular}{|c|c|c|c|}
\hline $\begin{array}{l}\text { Üç Cinsiyet (Ge- } \\
\text { nera) }\end{array}$ & $\begin{array}{l}\text { iki Cinsiyet (Ge- } \\
\text { nera) }\end{array}$ & Cinsiyetsiz & Dört ve daha fazla \\
\hline $\begin{array}{l}\text { Arnavutça } \\
\text { Boşnakça } \\
\text { Almanca } \\
\text { Yunanca } \\
\text { Hırvatça } \\
\text { Latince } \\
\text { Makedonca } \\
\text { Rumca } \\
\text { Felemenkçe } \\
\text { Polonya Dili } \\
\text { Rumence } \\
\text { Rusça } \\
\text { Sirpça } \\
\text { Slovakça } \\
\text { Slovence } \\
\text { Ukraynaca }\end{array}$ & $\begin{array}{l}\text { Aramice } \\
\text { Fransizca } \\
\text { ibranice } \\
\text { Hintçe } \\
\text { Arapça } \\
\text { İtalyanca } \\
\text { Peştuca } \\
\text { Portekizce } \\
\text { Pencap Dili } \\
\text { Çingenece } \\
\text { İspanyolca } \\
\text { Urdu Dili }\end{array}$ & $\begin{array}{l}\text { Türkçe } \\
\text { Çince } \\
\text { Dari } \\
\text { Ingilizce } \\
\text { Japonca } \\
\text { Korece } \\
\text { Farsça } \\
\text { Tamilce } \\
\text { Tayland Dili } \\
\text { Ermenice } \\
\text { Macarca } \\
\text { Vietnam } \\
\text { Dili }\end{array}$ & $\begin{array}{l}\text { Afrika Dilleri: } \\
\text { Godie } \\
\text { Kisi } \\
\text { Fula, Babungo, Zan- } \\
\text { de } \\
\text { Zulu, Shona; } \\
\text { Swahili } \\
\text { Avustralya Dilleri: } \\
\text { Dyirbal (Pama- } \\
\text { Nyunga, Avustralya- } \\
\text { ca) }\end{array}$ \\
\hline
\end{tabular}

Tablo 1

\section{Almanca ve Türkçede Cinsiyet Kavramı}

Dilbilgisel cinsiyet, Almancada morfoloji ve cümle yapısında biyolojik cinsiyetten daha önemli bir yere sahiptir. Öğelerin başka öğelerle uyumu dilbilgisel 
cinsiyet yoluyla sağlanmaktadır. Bir ismin dilbilgisel cinsiyeti o isimle birlikte öğrenilmek zorundadır. İsimlerin dilbilgisel cinsiyetleri artikeller ile gösterilmektedir ve isimlerin dilbilgisel cinsiyet ile tanımları, bazı istisnai kurallar haricinde, genel olarak bir kurala bağlı değildir:

Eril (maskulin): der Stuhl (sandalye)

Dişil (feminin): die Tür (kapı)

Yansız (neutral): das Fenster (pencere)

Bazı durumlarda dilbilgisel cinsiyet istisnai kurallar ile anlamdan veya şekilden çıkarılabilmektedir:

1. Belli isim ekleri dilbilgisel cinsiyeti göstermektedir:

- -ung, -heit, -keit, -schaft, -tät -ei, -in gibi isim ekleri her zaman dişil etki gösterirler ve isme die artikelini tanımlarlar: die Zeitung (gazete), die Übung (alıştırma), die Geschwindigkeit (hız), die Schönheit (güzellik), die Gesellschaft (toplum), die Universität (üniversite), die Lehrerin (bayan öğretmen).

Yunanca ve Latince kökenli -ion, -tät, -enz, -ie, -ik, -sis, -ur ekleri de dişil etki göstererek isme die artikelini tanımlarlar: die Akzeptanz (kabul), die Effizienz (yeterlik), die Loyalität (bağlılık), die Revolution (devrim), die Fraktur (kırlma), die Basis (temel), die Sympathie (sempati), die Chronik (kronik).

- -ling, -ig, -ich, -er isim ekleri her zaman eril etki gösterirler ve isme der artikelini tanımlarlar: der Honig (bal), der König (kral), der Pfirsich (şeftali), der Winzling (ufaklık), der Arbeiter (işçi)..

- Yunanca ve Latince kökenli -ismus, ant, -ast, -ent, -ist, -or, -us isim ekleri her zaman eril etki gösterirler ve isme der artikelini tanımlarlar: der Praktikant (stajyer), der Gymnasiast (liseli), der Patient (hasta), der Rassist (ufaklık), der Rassismus (ırkçlık), der Nationalismus (milliyetçilik), der Optimismus (iyimserlik), der Pessimist (kötümser), der Actor (aktör), der Luxus (lüks), der Artist (sanatçı). 
- -chen, -lein, -tel, -tum, -nis isim ekleri her zaman yansız etki gösterirler ve isme das artikelini tanımlarlar: das Kaninchen (tavşan), das Hähnchen (piliç), das Viertel (çeyrek, muhit), das Altertum (eski çă̆), das Häuschen (küçük ev), das Gärtlein (bahçecik).

Yunanca ve Latince kökenli -em, -in, -um, -ma, und -ment ekleri de yansız etki göstererek isme das artikelini tanımlarlar: das Medikament (ilâç), das System (sistem), das Benzin, das Maximum, das Minimum, das Komma (virgül), das Abonnement (katılım), das Enigma (bilmece, gizem), das Zeugnis (belge, sertifika), das Verhältnis (oran, ilgi), das Ergebnis (sonuç).

2. Gün zamanları, haftanın günleri, aylar, mevsimler, dört ana yön, yağış türleri der artikeli ile eril olarak tanımlanırlar: der Morgen (sabah), der Montag (pazartesi), der Januar (ocak), der Sommer (yaz), der Norden (kuzey), der Regen (yağmur). İstisna: die Nacht (gece), die Woche (hafta), das Jahr (yil).

3. Toprak ve kaya türleri der artikeli ile eril olarak tanımlanırlar: der Stein (taş), der Sand (kum), der Granit (granit), der Marmor (mermer). İstisna: die Kreide (tebeşir)

4. Canlı varlıkların isimlerindeki -e eki ismi der ile tanımlar: der Junge (erkek çocuk), der Löwe (aslan), der Kollege (meslektaş), der Experte (uzman). İstisna: die Katze (kedi).

5. Fiil kökünden oluşturulan isimler der artikeli ile tanımlanırlar: der Plan (plan), der Lauf (akış), der Flug (uçuş), der Wunsch (istek), der Anfang (başlangıç), der Eingang (giriş). İstisna: die Arbeit (iş), das Spiel (oyun).

6. Para isimleri der artikeli ile tanımlanırlar: der Dollar, der Franc, der Franken, der Rubel, der Yen. İstisna: die Mark, das Pfund, die Krone, die Peseta, die Lira.

7. Araba markalarının isimleri der artikeli ile tanımlanırlar: der Audi, der Fiat, der Mercedes, der Saab, der Volkswagen, der BMW. 
8. Alkollü içecekler der artikeli ile tanımlanırlar: der Kognak, der Likör, der Sherry, der Wodka, der Wein (şarap), der Sekt (köpüklü şarap). İstisna: das Bier (bira).

9. Metall ve madde isimleri das artikeli ile tanımlanırlar: das Metall, das Eisen (demir), das Gold, das Salz (tuz), das Gas, das Kupfer (bakır), das Uran (uranyum). İstisna: der Stahl (çelik), der Schwefel (kükürt), die Bronze, die Kohle (kömür).

10. Mastardan oluşturulan isimler das artikeli ile tanımlanırlar: das Essen (yemek), das Leben (yaşam), das Rechnen (hesaplama), das Zeichnen.

11. ge-, öneki ile oluşturulan isimler das artikeli ile tanımlanırlar: das Gebirge (sıradağ), das Gewicht (ă̆ırlık).

12. Kesir ve parça isimleri das artikeli ile tanımlanırlar: das Achtel (sekizlik), das Viertel (çeyrek).

Cinsiyetin, Türkçede Almancadaki gibi dilbilgisel bir düzlem içerisinde yapılanmamış olması, dilsel bir kategori oluşturmadığı anlamına gelmemektedir. Whorfa göre, bu gibi durumlarda dillerde açık kategoriler gibi kapalı kategorileri de düşünmek gerekmektedir. Whorf, açık kategoriler ile cümlede, kategorinin açıkça göründüğü şekilsel belirtilerden bahsetmektedir. Kapalı kategoriler ise cümlenin şekilsel belirtileriyle ilgisi bulunmayan ve sadece belli başlı cümle tiplerinde görülebilen sınıflandırmada yer almaktadır. (Braun 2000: 13) Buna göre Türkçe, kişisel terimler ile dilsel bir kategori oluşturmaktadır. (Braun 2000: 15) Kişisel terimler, daha önce de belirtildiği gibi, biyolojik cinsiyet ile örtüşen sözcüklerdir. Bunlar kadın, erkek, oğlan, kız, bayan, bay gibi anlamsal boyutta cinsiyete işaret eden tanımlamalardır. Anne, baba, oğul, kız, teyze, amca, hala, dayı, enişte, görümce, yenge, baldız ve bunlar gibi birçok "akrabalık teriminde, Türkçe, geniş kapsamlı bir sözcüksel cinsiyet" (Braun 2000: 49) tanımı göstermektedir. Bu akrabalık terimleriyle beraber hanım, bay, bayan, bey, hanımefendi, beyefendi gibi sözcükler aynı zamanda hitap olarak da kullanılmaktadır ve böylece dilsel bir kategori oluşturmaktadır. (Braun 2000: 49)

Türkçeye Arapçadan girmiş olan -e isim eki de cinsiyet ayrımında dilsel bir kategori oluşturmaktadır. Bu kullanım günümüzde pek yaygın olmasa da bazı durumlarda kendini hissettirmektedir. Müdür - müdire, rakip - rakibe, memur - memure gibi sözcüklerde cinsiyet ayrımını gösteren -e takısı kural olarak bayan tanımlarına eklenmektedir. Bunun yanı sıra bu ek özel adlarda kendini daha 
etkili bir şekilde göstermektedir: Cemil - Cemile, Fethi - Fethiye, Hamit - Hamide, Mevlüt - Mevlüde. (Braun 2000: 51) Ayrıca, Kraliçe/tanrıça sözcüklerindeki, Slav dillerinden Türkçeye girmiş olan -içe ve -ça; dansör/dansöz sözcüklerinin, Türkçeye Fransızcadan girmiş olan -ör ve -öz; aktör/aktris sözcüklerindeki, yine Türkçeye Fransızcadan girmiş olan -ör ve -is sonekleri Türkçede, cinsiyet tanımlı dilsel kategoriler oluşturmaktadır. (Braun 2000: 52)

Adların dilbilgisel cinsiyetleri Almancada 'der', 'die', 'das' belirli artikellerinde ve 'ein', 'eine', 'ein' belirsiz artikellerinde tanımlanmaktadır. Bu artikeller ve sıfatlar dilbilgisel cinsiyete bağımlıdır ve dilbilgisel cinsiyetin işaret ettiği isim hallerine ve sayı durumlarına göre çekimlenerek, ismi, uygun olan şekilde yapılandırmaktadırlar. Belirli artikellerin nominatif yani yalın halleri Türkçede bir karşılık bulamamaktadır. Örneğin: Das Kind kommt. Çocuk geliyor. Cümlesi ile Türkçede bir karşılık bulmaktadır. Türkçe cümledeki çocuk sözcügü bir cinsiyet tanımı ile belirtilmemiştir. Aynı şekilde, Almancadaki 'ein', 'eine', 'ein' belirsiz artikellerini tanımlayabilecek 'bir' belirsiz artikeli Türkçede hiçbir cinsiyet kavramını gösterememektedir:

- Die Frauen haben einen Kuchen gebacken. (Kadınlar bir pasta pişirdiler.)

Bu cümledeki "einen" belirsiz artikeli, der tanımlı ismin Almancadaki belirtme durumunu (ismin $\mathrm{i}$ hali) göstermektedir ve Türkçede sadece "bir" karşıllğını bulmaktadır. Oysa Almancada, cümledeki “einen” sözcüğünden bunun bir belirsiz artikel olduğunu, aynı zamanda der tanımlı eril bir isme ait olduğunu ve de ismin -i hali olan belirtme durumunu gösterdiğini anlamak mümkündür. Bu durumu Türkçede cümle içerisinde ancak 'Kadınlar pastayı pişirdiler' şeklinde ifade etmek mümkündür.

Dilbilgisel cinsiyet bulunmayan bir dil olarak Türkçe, Almancadaki 'er' (eril o), 'sie' (dişil o), 'es' (yansız o) 3. tekil şahıs zamirlerine sadece 'o' genel 3. tekil şahıs zamiri ile karşılık verebilmektedir. Bundan dolayı özellikle çevirilerde bazı sorunlar yaşanmaktadır. Çünkü Almancanın gerektirdiği cinsiyet kavramı Türkçede tanımlanamamaktadır. Örneğin:

Ayşe und Ahmet haben heute wich- $\rightarrow$ Ayşe ile Ahmet bugün önemli işler tige Sachen erledigt. hallettiler. 
Sie hat für ihre Prüfung gearbeitet. $\rightarrow \mathbf{O}$ kendi (veya onun) sınavı için çalıştı.

Er hat seine Doktorarbeit fertiggeschrieben.

$\rightarrow$ O kendi (veya onun) doktora çalışmasının yazımını bitirdi.

Buradaki kısa metinde iki kişiden bahsedilmektedir. Bunlar Ayşe ve Ali isimlerini taşıyan, biri bayan, ikincisi erkek olan iki özne. Özel isimlerin Türkçeye çeviriminde bir sıkıntı bulunmamaktadır. Almanca cümledeki Ayşe ve Ali, Türkçedeki anlamı ile ve yapısı ile aynı şekilde kullanılmaktadır. ikinci cümlelerin çevirisinde, Türkçe cümlede bir belirsizlik ortaya çıkmaktadır. Ayşe özel ismi, 3. tekil şahıs olarak ifade edildiğinde, Almancada "sie" zamiri ile karşılık bulmaktadır. "Sie" zamiri Almancada 3. tekil şahıs dişil zamiri olarak tanımlanmaktadır ve "die" belirli artikelinin yerini doldurmaktadır. Almanca cümleyi okuyan kişi, bunun bir dişil özne, burada bir bayan, olduğunu gayet rahat anlamaktadır. Türkçe cümledeki belirsizlik "o" 3. tekil şahıs tanımında bulunmaktadır. Çünkü burada "o" nun dişi mi, yoksa eril mi, yoksa yansız mü olduğu anlaşılamamaktadır. Aynı durum bir sonraki cümledeki "er" tanımı ile de ortaya çıkmaktadır. Almancasında, eril olduğunun gayet rahat anlaşıldığı "er", Türkçede yine "o" ile karşılık bulmaktadır ve burada da cinsiyetin belirsizlik durumu ortaya çıkmaktadır. Aynı şekilde bu cümlelerdeki iyelik zamirlerinde de bir belirsizlik bulunmaktadır. Almancadaki "ihre" iyelik zamiri dişil bir iyelik belirtmektedir. Yani sahip olan kişinin dişil bir cinsiyeti vardır ve "die" belirli artikelini taşımaktadır. "sein" iyelik zamiri ise eril cinsiyetli bir öznenin tanımıdır ve bu özne "der" belirli artikelini taşımaktadır. Bu iyelik tanımları Türkçede yine bir cinsiyet göstermeyen "kendi" ifadesi ile tanımlanmaktadır ki bu da anlamda bir belirsizlik oluşturmaktadır. Bu gibi kişi zamirlerinin yer aldığı cümleler Almanca ile Türkçe arasında yaşanan en büyük sorunlardan birini oluşturmaktadır. Türkçede bulunmayan er, sie, es 3 . Tekil şahıs tanımları çeviri işlemlerinde zorluklar yaşanmasına sebep olmaktadır. Türkçe bir metindeki "o" şahıs zamiri Almancaya tercüme edilirken, bağlamda söz konusu şahıs tanımı olmadı̆̆ı sürece, "er", "sie", "es" sözcüklerinden hangisine denk geleceği konusunda veya tersi durumda, belirsizlikler oluşmaktadır:

- “O, kardeşinin arkadaşıı bekliyor." (Braun 2000: 49)

Cümlesinin Almancaya çevrilmesinde fazla sayıda alternatif ortaya çıkmaktadır. Türkçe cümlede, özneyi "o" tanımı oluşturmaktadır. Bunu Almancaya çevirirken üç sözcük arasında ayrım yapmak gerekmektedir. Böylece daha özneden başlayarak elimizde üç farklı cümle bulunmaktadır: 
- Sie wartet. (O bekliyor.)

- Er wartet. (O bekliyor.)

- Es wartet. (O bekliyor.)

Türkçe cümlenin diğer bir öğesi olan nesnede de aynı karmaşa yaşanacaktır. Arkadaşını sözcügü Türkçede kadın - erkek tanımlarının her ikisinde de kullanılırken, Almancada Freund /Freundin sözcükleri buna karşılık gelmektedir. Eğer bağlamda bunun cinsiyeti tanımlanmıyorsa, yine cümle birkaç alternatif bulacaktır:

- Sie wartet auf die Freundin. $\quad \rightarrow \quad$ O, arkadaşı bekliyor.

- Er wartet auf die Freundin. $\quad \rightarrow \quad$ O, arkadaşı bekliyor.

- Es wartet auf die Freundin. $\quad \rightarrow \quad 0$, arkadaşı bekliyor.

- Sie wartet auf den Freund. $\quad \rightarrow \quad$ O, arkadaşı bekliyor.

- Er wartet auf den Freund. $\quad \rightarrow \quad 0$, arkadaşı bekliyor.

- Es wartet auf den Freund. $\quad \rightarrow \quad$ O, arkadaşı bekliyor.

Türkçe cümledeki 'kardeşinin' sözcüğü de yine Almancaya 'Schwester' ve 'Bruder' olmak üzere iki farklı seçenek ile yansıma bulmaktadır:

- Sie wartet auf die Freundin ihrer Schwester/ihres Bruders. (O, kardeşinin arkadaşını bekliyor.)

- Er wartet auf die Freundin seiner Schwester/seines Bruders. (O, kardeşinin arkadaşını bekliyor.)

- Es wartet auf die Freundin seiner Schwester/seines Bruders. (O, kardeşinin arkadaşını bekliyor.)

- Sie wartet auf den Freund ihrer Schwester/ihres Bruders. (O, kardeşinin arkadaşını bekliyor.)

- Er wartet auf den Freund seiner Schwester/seines Bruders. (O, kardeşinin arkadaşını bekliyor.)

- Es wartet auf den Freund seiner Schwester/seines Bruders. (O, kardeşinin arkadaşını bekliyor.)

Bu cümleleri tek bir cümleye dönüştürme eyleminde ise şöyle bir cümle ortaya çıkmaktadır:

- Sie/er/es wartet auf die Freundin/den Freund ihrer/seiner Schwester; ihres/seines Bruders. 
Örneklerden de anlaşılacağı gibi, Almancada dilbilgisel cinsiyet zamirlerde büyük bir etki göstermektedir. Bu zamirlerin her birinin ayrı ayrı hal ve durum çekimleri de bulunmaktadır. Bu çekimler örnek cümlelerde de dikkatleri çekmektedir. Cümlelerdeki ihr/sein zamirleri genitif yani - in haline işaret etmektedir. Almancadaki 'er' (eril o), 'sie' (dişil o), 'es' (yansız o) 3. tekil şahıs zamirlerinin Almancadaki dört hal çekimlerini, Türkçedeki karşılıkları ile şöyle bir tabloda ele alalım:

\begin{tabular}{|c|c|c|c|}
\hline ALMANCA & $\begin{array}{c}\text { Maskulin } \\
\text { (eril) }\end{array}$ & $\begin{array}{l}\text { Neutral } \\
\text { (yansiz) }\end{array}$ & $\begin{array}{c}\text { Feminin } \\
(\text { dișil) }\end{array}$ \\
\hline $\begin{array}{l}\text { Nominativ (yalın } \\
\text { hal) }\end{array}$ & er (eril o) & es (yansız o) & sie (dişil o) \\
\hline Akkusativ (i hali) & ihn (eril onu) & es (yansız onu) & sie (dişil onu) \\
\hline Dativ (e hali) & ihm (eril ona) & ihm (yansız ona) & ihr (dişil ona) \\
\hline Genitiv (in hali) & $\begin{array}{l}\text { seiner (eril } \\
\text { onun) }\end{array}$ & $\begin{array}{l}\text { seiner (yansız } \\
\text { onun) }\end{array}$ & $\begin{array}{l}\text { ihrer (dişil } \\
\text { onun) }\end{array}$ \\
\hline \multicolumn{4}{|l|}{ TÜRKÇE } \\
\hline $\begin{array}{l}\text { Nominativ (yalın } \\
\text { hal) }\end{array}$ & o & $\mathbf{o}$ & o \\
\hline Akkusativ (i hali) & onu & onu & onu \\
\hline Dativ (e hali) & ona & ona & ona \\
\hline Genitiv (in hali) & onun & onun & onun \\
\hline
\end{tabular}

Tablo 2

Tablo2'de de açıkça görüldüğü gibi, Almancadaki her bir 3. Tekil şahıs zamiri, ismin dört halinde birbirinden farklı tanımlar almaktadırlar. Bunların Türkçe karşılı̆̆ ise her üç şahıs zamirinde sırasıyla o, onu, ona ve onun tanımları ile anlam bulmaktadır. 


\begin{tabular}{|l|c|c|c|}
\hline \multicolumn{1}{|c|}{ Belirli Artikel } & $\begin{array}{c}\text { Maskulin } \\
\text { (eril) }\end{array}$ & $\begin{array}{c}\text { Neutral } \\
\text { (yansı) }\end{array}$ & $\begin{array}{c}\text { Feminin } \\
\text { (dişil) }\end{array}$ \\
\hline Nominativ (yalın hal) & der & das & die \\
\hline Akkusativ (i hali) & den & das & die \\
\hline Dativ (e hali) & dem & dem & der \\
\hline Genitiv (in hali) & des & des & der \\
\hline Belirsiz Artikel & & & ein \\
\hline Nominativ (yalın hal) & ein & eine \\
\hline Akkusativ (i hali) & einen & eine \\
\hline Dativ (e hali) & einem & einem & einer \\
\hline Genitiv (in hali) & eines & eines & einer \\
\hline
\end{tabular}

Tablo 3

Türkçede ismin altı hali bulunmaktadır. İsmin eksiz temel şekli yalın hali oluştururken diğer halleri belirli ekler yapılandırmaktadır. Türkçedeki bu altı halden dört tanesi, Almancada mevcut olan, Tablo 3'deki dört hal ile karşılık bulmaktadır. Almancada karşılık bulunmayan Türkçe de (Lokatif) ve den (Ablatif) halleri ise yerine göre Almancadaki in, von, aus, zu, bei, durch, über gibi edatlar ile anlamlandırılabilmektedir:

$$
\begin{array}{lll}
\text { evde } & \rightarrow \text { zu Hause } & \rightarrow \text { in dem Haus } \\
\text { evden } & \rightarrow \text { von dem Haus } & \rightarrow \text { aus dem Haus } \\
\text { bahçeden } & \rightarrow \text { durch den Garten } & \rightarrow \text { von/aus dem Garten } \\
\text { duvardan } & \rightarrow \text { über die Mauer } &
\end{array}
$$

Almancadaki bir başka dilbilgisel cinsiyet kullanım alanı ise örneklerde de görüldüğ̈ gibi edatlarda ortaya çıkmaktadır. Almancada bulunan her bir edat ki çok fazla edat mevcuttur - kendi durumuna göre isme belli bir hal aldırarak ismin cinsiyetini belirten artikeli çekimlemektedir ve Almancadaki edatlar yerine Türkçede belli ekler veya Türkçedeki edatlar kullanılmaktadır: 
Das Kind sitzt auf dem Stuhl. $\quad \rightarrow$ Çocuk sandalyede oturuyor.

Der Lehrer fuhr mit dem Bus in die $\rightarrow$ Öğretmen okula otobüsle gitti.

Schule.

Der Mann spricht über den Unfall. $\rightarrow$ Adam, kaza hakkında konuşuyor.

Dilbilgisel cinsiyet Almancada sıfat çekimlerinde de etkili bir yapıdır. İsmin alacağı hale göre dilbilgisel cinsiyeti gösteren artikel sıfat ile birlikte veya artikel bulunmadan sıfat tek başına çekimlenmektedir:

$$
\begin{array}{lll}
\text { das schöne Mädchen } & \rightarrow & \text { güzel kız } \\
\text { ein schönes Mädchen } & \rightarrow & \text { güzel bir kız } \\
\text { schönes Mädchen } & \rightarrow & \text { güzel kız }
\end{array}
$$

Dilbilgisel cinsiyet yapılandırdığı bütün çekimlerde hal belirtisinin yanı sıra sayı (tekil - çoğul) belirtisinde de bulunmaktadır. Ayrıca tekili ve çoğulu aynı olan isimlerde, dilbilgisel cinsiyet sayı belirtisini yapmaktadır:

$$
\begin{array}{lll}
\text { das Kind - die Kinder } & \rightarrow & \text { çocuk - çocuklar } \\
\text { dem Kind - den Kindern } & \rightarrow & \text { çocuğa - çocuklara } \\
\text { der Löffel - die Löffel } & \rightarrow & \text { kaşı - kaşıklar } \\
\text { den Löffel - die Löffel } & \rightarrow & \text { kaşı̆̆ - kaşılkları }
\end{array}
$$

\section{Sonuç}

Dilbilgisel cinsiyet ile biyolojik cinsiyetin ele alındığı bu çalışmada her iki kavramın gelişimine, tanımına, tarihsel ve yapısal oluşumuna değinilerek konu ile ilgili bir açıklama yapılmaya çalışılmıştır. Bununla beraber bu kavramların dünya dillerindeki önemi de burada vurgulanmışırı. Bu çalışma ile Almancadaki dilbilgisel cinsiyetin karmaşık bir uygulama alanına sahip olduğu bir kez daha görülmektedir. Bu karmaşık yapıda isimlerin dilbilgisel cinsiyeti ile biyolojik cinsiyetlerinin kesinlikle birbirinden farklı iki ayrı olgu oldukları göz ardı edilmemelidir. Burada ortaya çıkan sonuçlardan bir tanesi, dilbilgisel cinsiyetin ortaya çıkış kuramlarının her birinin kendine özgü kabul edilebilirlik taraflarının bulunması, buna rağmen neden böyle bir yapının gerekli görüldüğünün yine de tamamen açıklanamayarak belli tahminlerden öteye gidememiş olmasıdır. Bu durumda, böyle bir dildeki dilbilgisel cinsiyetin, bazı istisnai durumlar hariç, tamamen tesadüfî bir yapılanma gösterdiğini kabul etmek ilk adım olacaktır. 
Bu çalışmada ayrıca, Türkçede bulunmayan ve Türkiye'de çok dar bir alanda tanınan bir dilbilgisel öğe ele alınarak tanıtıldı. Bunun yanı sıra bu dilbilgisel yapının hem dil öğrenimi açısından, hem çeviri eylemi açısından, hem de bu öğenin Almanca ile Türkçe arasındaki farklıłıklarını ve benzerliklerini ortaya koyma amacı ile bu çalışma gerçekleştirilmiştir. Dillerin cinsiyet ayımı her dilde farklı bir boyutta gerçekleşmektedir. Yapılan karşılaştırma sonucu Türkçe ve Almancanın iki farklı dil olarak cinsiyet açısından çok farklı nitelikte bulundukla$\mathrm{rı}$, bu iki dilin dilbilgisel yapı olarak asla birbiriyle uyuşma gösteremeyecekleri, buna rağmen her iki dilde de dil içi donanımın diğerindeki anlamlara karşılık gelebileceği görüldü. Bunun yanı sıra dil öğreniminde çokça öne sürülen dilbilgisel cinsiyetin zorluk durumu bu çalışmada da öne çıkmış bulunmaktadır ve bu çalışma ile Almanca öğrenen Türkler için yol gösterici örnekler ve karşılaştırmalar ortaya konulmuştur.

\section{KAYNAKÇA}

AKSAN, Doğan. Her Yönüyle Dil Ana Çizgileriyle Dilbilim 3, Ankara: Türk Dil Kurumu, 1998.

BEWER, Franziska. Der Erwerb des Artikels als Genus-Anzeiger im deutschen Erstspracherwerb, ZAS Papers in Linguistics 33, 2004, $87-140$.

BRAUN, Friederike. Geschlecht im Türkischen, Wiesbaden: Otto Harrassowitz Verlag, 2000 465 sayfa.

DROSDOWKSi, Günther. Duden-Zweifelsfälle der deutschen Sprache (Duden 9), Mannheim/ Wien/ Zürich: Dudenverlag, 1972.

FISCHER, Rudolf-josef. Genuszuordnung. Theorie und Praxis am Beispiel des Deutschen, Frankfurt am Main, Berlin, Bern, Bruxelles, New York, Oxford, Wien: 2 Abb., 24 Tab., 1 Graf. Europäische Hochschulschriften: Reihe 21, Linguistik. Bd. 281. 2005.

GERBER, Rudolf. Die Sprache, BoD - Books on Demand, Nordersted: 2008 - 52 Seiten.

HEINA, Michael. Entstehungstheorien zum Genus der Sprache, Studienarbeit, Norderstedt 1. Auflage: GRIN - Verlag für akademische Texte, 2006.

KLANN - DELIUS, Gisela. Sprache und Geschlecht, Stuttgart: Metzler, 2005 - 230 Seiten.

LYONS, John. Einführung in die moderne Linguistik, aus dem Englischen von W. Un G. Abraham, München: C. H. Beck'sche Verlagsbuchhandlung, 5. Auflage, 1980.

MüLLER, Friedrich. Das grammatische Geschlecht (Genus): ein sprachwissenschaftlicher Versuch : (aus dem Februar-Hefte des Jahrg. 1860 der Sitzungsberichte der phil.-hist. Classe der K. Akademie der Wissenschaften, XXXIII. Band, S. 373, besonders abgedruckt) (Google eBook), In Kommi. bei Karl Gerold's Sohn, Wien 1860 - 26 Seiten.

PITTNER, Karin. “Genus, Sexus und das Pronomen wer”, Erschienen 1998 in: Robert J. Pittner/Karin Pittner (eds.), Beiträ ge zu Sprache und Sprachen 2. Vorträge der 5. Münchner Linguistik-Tage 1995, München: lincom europa, 153-162.

REISS, Kristina. „Von Feministischer Linguistik zu Genderbewusster Sprache“, İçinde: Ruth Becker,Beate Kortendiek; Handbuch Frauen- und Geschlechterforschung: Theorie, Methoden, Empirie, VS Verlag, Wiesbaden 2011 - 968 Seiten.

POBER, Maria. Gendersymmetrie: Überlegungen zur geschlechtersymmetrischen Struktur eines Genderwörterbuches im Deutschen, Würzburg: Königshausen \& Neumann, 2007 - 561 Seiten. 
SCHOLZ, Cosima. Genuszuweisung im Deutschen, Magisterarbeit Institut für deutsche Sprache und Literatur der Universität zu Köln Gutachterin: Frau Prof. Dr. Beatrice Primus, Zentrum Sprachenvielfalt und Mehrsprachigkeit, Februar 2007.

SOWINSKI, Bernhard. Germanistik Teil I Sprachwissenschaft, Köln - Wien: Böhlau Verlag, 1974.

TAFEL, Karin. Die Frau im Spiegel der russischen Sprache, Wiesbaden: Otto Harrassowitz Verlag, 1997.

VARDAR, Berke. Açıklamalı Dilbilim Terimleri Sözlüğü, İstanbul: ABC Kitabevi, 1998.

WEBER, Doris. Genus. Zur Funktion einer Nominalkategorie, exemplarisch dargestellt am Deutschen. (Europäische Hochschulschriften: Reihe 1, Deutsche Sprache und Literatur; 1808). Frankfurt am Main: Peter Lang, 2001.

Lisa Irmen ve Claudia Sander (2000), "Richtlinien und Beispiele für einen nicht-sexistischen Sprachgebrauch"

http://www.psychologie.uniheidelberg.de/personen/frauenbeauftragte/hintergrund.html, 16.08.2006. 